\title{
The c-Jun N-terminal kinase signaling pathway mediates chrysotile asbestos-induced alveolar epithelial cell apoptosis
}

\author{
PENG LI $^{1 *}$, TIE LIU ${ }^{2 *}$, DAVID W. KAMP ${ }^{3}$, ZIYING LIN $^{1}$, YAHONG WANG ${ }^{1}$, \\ DONGHONG LI ${ }^{1}$, LAWEI YANG ${ }^{1}$, HUIJUAN HE ${ }^{1}$ and GANG LIU ${ }^{1}$ \\ ${ }^{1}$ Clinical Research Center, Guangdong Medical College, Zhanjiang, Guangdong 524001; \\ ${ }^{2}$ Department of Hematology, The First Affiliated Hospital, Medical School of Xi'an Jiaotong University, \\ Xi'an, Shaanxi 710061, P.R. China; ${ }^{3}$ Department of Medicine, Division of Pulmonary and Critical Care Medicine, \\ Jesse Brown Veterans Affairs Medical Center and Northwestern University Feinberg School of Medicine, Chicago, IL 60611, USA
}

Received March 26, 2014; Accepted July 22, 2014

DOI: $10.3892 / \mathrm{mmr} .2014 .3119$

\begin{abstract}
Exposure to chrysotile asbestos exposure is associated with an increased risk of mortality in combination with pulmonary diseases including lung cancer, mesothelioma and asbestosis. Multiple mechanisms by which chrysotile asbestos fibers induce pulmonary disease have been identified, however the role of apoptosis in human lung alveolar epithelial cells (AEC) has not yet been fully explored. Accumulating evidence implicates AEC apoptosis as a crucial event in the development of both idiopathic pulmonary fibrosis and asbestosis. The aim of the present study was to determine whether chrysotile asbestos induces mitochondria-regulated (intrinsic) AEC apoptosis and, if so, whether this induction occurs via the activation of mitogen-activated protein kinases (MAPK). Human A549 bronchoalveolar carcinoma-derived cells with alveolar epithelial type II-like features were used. The present study showed that chrysotile asbestos induced a dose- and time-dependent decrease in A549 cell viability, which was accompanied by the activation of the MAPK c-Jun N-terminal kinases (JNK), but not the MAPKs extracellular signal-regulated kinase $1 / 2$ and p38. Chrysotile asbestos was also shown to induce intrinsic AEC apoptosis, as evidenced by the upregulation of the pro-apoptotic genes Bax and Bak,
\end{abstract}

Correspondence to: Professor Gang Liu, Clinical Research Center, Guangdong Medical College, 57 Renming Ave, Zhanjiang, Guangdong 524001, P.R. China

E-mail: gangliu11@gdmc.edu.cn

Dr David W. Kamp, Department of Medicine, Division of Pulmonary and Critical Care Medicine, Jesse Brown Veterans Affairs Medical Center and Northwestern University Feinberg School of Medicine, 240 E. Huron St., Chicago, IL 60611-3010, USA

E-mail: d-kamp@northwestern.edu

*Contributed equally

Key words: chrysotile asbestos, apoptosis, c-Jun N-terminal kinases (JNK), mitochondrial dysfunction alongside the activation of caspase-9, poly (ADP-ribose) polymerase (PARP), and the release of cytochrome $c$. Furthermore, the specific JNK inhibitor SP600125 blocked chrysotile asbestos-induced JNK activation and subsequent apoptosis, as assessed by both caspase- 9 cleavage and PARP activation. The results of the present study demonstrated that chrysotile asbestos induces intrinsic AEC apoptosis by a JNK-dependent mechanism, and suggests a potential novel target for the modulation of chrysotile asbestos-associated lung diseases.

\section{Introduction}

Environmental or occupational exposure to asbestos fibers increase the risk for chronic respiratory diseases, including interstitial lung fibrosis (for example, asbestosis), lung cancer, and pleural malignant mesothelioma (1-4). Asbestos fibers are naturally found in rocks and soils and consist of six distinct types: Crocidolite, amosite, anthophyllite, tremolite, actinolite and chrysotile $(4,5)$. Chrysotile asbestos is the sole serpentine type of asbestos (6,7), which has been widely used as an industrial material in China. The mechanisms of injury to the cells of the lung and pleura, resulting in lung diseases, following asbestos exposure have not yet been fully established, despite extensive investigations over several decades $(1,2,4,7)$. All forms of asbestos, including chrysotile, are carcinogenic, and have been previously shown to promote iron-derived free radical formation in vitro, injure lung target cells, and induce asbestosis, lung cancer, and mesothelioma in humans $(1,2,4,7)$. As previously reviewed, accumulating evidence firmly implicates alveolar epithelial cell (AEC) apoptosis as an important early event in the pathophysiology of idiopathic pulmonary fibrosis (IPF) and asbestosis $(2,4)$. Previous studies have shown that asbestos-induced pulmonary toxicity is mediated in part by lung epithelial cell mitochondrial dysfunction, mitochondrial reactive oxygen species production, DNA damage, p53 activation and mitochondria-regulated apoptosis $(2,4,7,8)$. Previous studies on lung epithelial cell mitochondria-regulated (intrinsic) apoptosis have focused solely on the effects of amphibole asbestos, including amosite and crocidolite, while the effects of chrysotile asbestos on lung epithelial cells is currently unknown (2-4,9-11). 
Asbestos pulmonary toxicity, including apoptosis, occurs partly by the activation of epidermal growth factor receptor and other receptors, resulting in the activation of the mitogen-activated protein kinase (MAPK) pathway, which includes p38, c-Jun N-terminal kinase (JNK) and extracellular signal regulated kinase (ERK 1/2) $(12,13)$. The MAPK p38 has been previously implicated in the chronic immune response elicited by asbestos in rat mesothelial cells (14). Furthermore, fibroblast growth factor-10 has been shown to decrease asbestos-induced DNA damage and apoptosis in AECs by modulating MAPK-ERK-dependent signaling that affects the mitochondria-regulated apoptosis pathway (15). Asbestos induces AEC plasticity through the MAPK-ERK signaling pathway (16). Protein kinase delta (PKC 8 )-dependent mechanisms have been implicated in mediating AEC intrinsic apoptosis, in part through $\mathrm{PKC} \delta$ phosphorylation of JNK which triggers pro-apoptotic Bcl-2-like protein 11 (Bim) expression (8). Whereas the ERK1/2-related anti-apoptotic pathways have been shown to be activated at lower asbestos concentrations as a survival response in tumor cells (8).

In the present study, it was hypothesized that chrysotile asbestos may induce AEC intrinsic apoptosis via the MAPK-JNK signaling pathway. To address this hypothesis, the effects of chrysotile asbestos on cell viability and DNA fragmentation were analyzed in human A549 bronchoalveolar carcinoma cells, with alveolar epithelial type II-like features. Chrysotile-induced A549 cell expression of activated JNK, ERK1/2, p38, B cell lymphoma-2 (Bcl-2) associated X protein (Bax), Bcl-2 homologous antagonist killer (Bak), cytochrome $c$, caspase-9 and poly (ADP-ribose) polymerase (PARP) proteins was also assessed by western blotting. Furthermore, the effects of the JNK inhibitor SP600125, on chrysotile asbestos-induced A549 cell apoptosis and JNK-PARP signaling were determined. The present study showed that chrysotile asbestos can induce intrinsic apoptosis in A549 cells through the JNK-dependent signaling pathway.

\section{Materials and methods}

Reagents. Dulbecco's modified Eagle's medium (DMEM) and fetal bovine serum (FBS) were obtained from Gibco-BRL (Carlsbad, CA, USA). Primary rabbit polyclonal antibodies against human phospho-JNK1/2, phospho-ERK1/2, phospho-p38, phospho-p53, JNK1/2, ERK1/2, p38, cytochrome $c$, PARP, Bax, Bak, and caspase-9 were purchased from Cell Signaling Technology, Inc. (Danvers, MA, USA), and an antibody against $\beta$-actin was purchased from Santa Cruz Biotechnology Inc. (Santa Cruz, CA, USA). The antibodies were used at a 1:2,000 dilution. The JNK inhibitor SP600125, was purchased from Calbiochem ${ }^{\circledR}$ (Merck Millipore, La Jolla, CA, USA). Polyvinylidene difluoride membrane (PVDF) was purchased from Millipore (Billerica, MA, USA). Cellular DNA Fragmentation ELISA kits were purchased from Roche (Basel, Switzerland), the DeadEnd ${ }^{\mathrm{TM}}$ Fluorometric terminal deoxynucleotidyl transferase-mediated dUTP nick-end labeling (TUNEL) system was purchased from Promega Corporation (Madison, WI, USA), and the PrimeScript Reverse Transcription (RT) Enzyme Mix kits and $S Y B R^{\circledR}$ Green polymerase chain reaction (PCR) reagent were purchased from Takara Biotechnology Co., Ltd. (Osaka,
Japan). All the reagents used throughout the study were of analytical or cell culture grade purity. Chrysotile asbestos was obtained from Mangya Moutain (Qinghai Province, China).

Pretreatment of chrysotile asbestos. Chrysotile asbestos fibers used in the following experiments were mined from Qinghai, China. The chrysotile asbestos used in the treatments had an average length of $7.8 \mu \mathrm{m}$, and an average diameter of $0.2 \mu \mathrm{m}$, which was confirmed using transmission electron microscopy. The fibers were prepared as described by previous methods (17). Briefly, fiber samples were weighed and crushed into an ultrafine powder, using a mechanical crusher (Xulang Machinery Equipment Co., Ltd, Guangzhou, China). Following ultra-sonication at $20 \mathrm{kHz}$ for $10 \mathrm{~min}$ using a bath-type sonicator (Q700; QSonica LLC, Newtown, CT, USA), the mixtures were centrifuged at 2,000 $\mathrm{x}$ g for $10 \mathrm{~min}$, the supernatants were removed and the pellets were washed with $2 \mathrm{ml}$ distilled water. Each chrysotile asbestos sample was then re-suspended in phosphate-buffered saline (PBS) for the cell treatment. A stock solution of the fibers $(5 \mathrm{mg} / \mathrm{ml})$ was sterilized by autoclaving and mixed to ensure a uniform suspension prior to dilution with tissue culture medium, ready for the cell treatment.

Cell culture. A549 human bronchoalveolar carcinoma-derived cells, with some features characteristic of alveolar epithelial type II cells, were obtained from the American Type Culture Collection (Manassas, VA, USA). The cells were cultured in a humidified chamber containing $5 \% \mathrm{CO}_{2}$ at $37^{\circ} \mathrm{C}$ and maintained in DMEM supplemented with $10 \%$ FBS and antibiotics (100 U/ml penicillin and $100 \mathrm{~g} / \mathrm{ml}$ streptomycin). For the experiments, A549 cells were plated in $35 \mathrm{~mm}$ diameter dishes ( $2 \times 10^{5}$ cells/dish). Following $24 \mathrm{~h}$ in culture, the medium was refreshed with $4 \mathrm{ml}$ medium containing chrysotile fibers at the indicated final concentrations.

Measurement of cell viability by trypan blue exclusion method. The trypan blue exclusion method is a classic cell procedure used for assessing cell viability. The cells were divided and cultured in six-well plates $\left(1 \times 10^{5}\right.$ cells/well) for $24 \mathrm{~h}$, followed by treatment with chrysotile asbestos at various concentrations for $24 \mathrm{~h}$. The cells were harvested and centrifuged (5810R; Eppendorf, Hamburg, Germany) to remove the medium. The cells were then washed in PBS three times and resuspended, resulting in a suspension of $1 \times 10^{6}$ cells $/ \mathrm{ml}$. The suspension was mixed with $0.4 \%$ trypan blue dye (Sigma-Aldrich, St. Louis, $\mathrm{MO}, \mathrm{USA}$ ) for $5 \mathrm{~min}$ at $25^{\circ} \mathrm{C}$. The unstained (viable) and stained (non-viable) cells were counted using a hemacytometer (Neubauer Improved; Marienfeld, Lauda-Königshofen, Germany) within $5 \mathrm{~min}$ in four microscope fields, at magnification $\mathrm{x} 40$, per well (>100 cells/field).

Detection of apoptotic cells. Experiments were performed using a cellular DNA fragmentation ELISA kit according to the manufacturer's instructions (Roche). A549 cells were labeled with $10 \mu \mathrm{M}$ bromodeoxyuridine (BrdU; Roche) at $1 \times 10^{5}$ cells $/ \mathrm{ml}$. BrdU-labeled cells $\left(1 \times 10^{4}\right)$ in $100 \mu 1$ were treated with varying concentrations $\left(100,150,200 \mu \mathrm{g} / \mathrm{cm}^{2}\right)$ of cell extract for a period of $4 \mathrm{~h}$. Following treatment, the cells were lysed with lysis buffer (20 mM Tris, $\mathrm{pH} 7.6$; $1 \%$ Triton X-100; 137 mM NaCl; 2 mM EDTA; $1 \mathrm{mM} \mathrm{Na}_{3} \mathrm{O}_{4} \mathrm{~V}$; 
$10 \mathrm{mM} \mathrm{NaF} ; 1 \mathrm{mM}$ DTT; $1 \mathrm{mM}$ phenylmethylsulfonyl fluoride; $10 \mu \mathrm{g} / \mathrm{ml}$ leupeptin and $10 \mu \mathrm{g} / \mathrm{ml}$ aprotinin) for $30 \mathrm{~min}$ at $25^{\circ} \mathrm{C}$, and the supernatants containing apoptotic fragments were obtained following centrifugation at $1,500 \mathrm{x} \mathrm{g}$ for $10 \mathrm{~min}$. The recovered samples $(100 \mu \mathrm{l})$ were transferred onto anti-DNA-coated 96-well flat-bottom microplates (Corning Inc., Corning, NY, USA). The plates were incubated for $90 \mathrm{~min}$ at $15-25^{\circ} \mathrm{C}$, and the wells were washed three times with washing buffer, which was provided in the DNA fragmentation ELISA kit, for 2-3 min per wash. The DNA bound to the coated microplates was denatured by nuclease treatment (exonuclease III solution, $37^{\circ} \mathrm{C}$ for $30 \mathrm{~min}$; Takara Biotechnology Co., Ltd), followed by the addition of $100 \mu 1$ anti-BrdU-peroxidase (POD; Roche) conjugate solution. The plates were incubated for an additional $90 \mathrm{~min}$ and were washed again with washing buffer. Following washing, $100 \mu \mathrm{l}$ of the substrate solution was added, and the plates were shaken until color development was deemed sufficient. The absorbance was measured at $450 \mathrm{~nm}$ following the addition of $25 \mu \mathrm{l}$ of stop solution (Roche).

TUNEL assay. DNA damage was assessed by TUNEL assay using an in situ Cell Death Detection kit with fluorescein-dUTP as a label, according to the manufacturer's instructions (Promega Corporation). A549 cells were plated onto confocal petri dishes and grown to confluence over $24 \mathrm{~h}$ in DMEM supplemented with $10 \%$ FBS, followed by treatment with chrysotile asbestos for $24 \mathrm{~h}$. Following incubation, the culture medium was removed and the cells were washed three times in PBS. The cells were then fixed with $4 \%$ paraformaldehyde (Sigma-Aldrich), permeabilized with $0.1 \%$ Triton X-1 00 (Sigma-Aldrich), and incubated in the dark at $37^{\circ} \mathrm{C}$ for $1 \mathrm{~h}$ in a TUNEL reaction mixture containing $50 \mu 1$ of a mixture of terminal deoxynucleotidyl transferase and dUTP. DAPI was added at $25^{\circ} \mathrm{C}$ for $10 \mathrm{~min}$ as a non-specific stain of the cellular nuclei. Five fields per dish of cells were randomly analyzed using a Leica TCS SP5 II confocal microscope (Leica, Wetzlar, Germany)(>100cells/field). Each DAPI-stained cell was categorized as apoptotic if green nuclear fluorescence was observed, or normal if no green fluorescence was observed.

Western blotanalysis. The treated cells were rinsed with ice-cold PBS and incubated with radioimmunoprecipitation assay lysis buffer containing $50 \mathrm{mM}$ Tris- $\mathrm{HCl}$ (pH 7.4), $150 \mathrm{mM} \mathrm{NaCl}$, $1 \%$ Triton-X $100,1 \%$ sodium deoxycholate, $0.1 \%$ sodium dodecyl sulfate (SDS), $1 \mathrm{mM}$ ethylenediaminetetraacetic acid, $1 \mathrm{mM}$ sodium fluoride, $1 \mathrm{mM}$ phenylmethanesulfonyl fluoride, $10 \mu \mathrm{g} / \mathrm{ml}$ aprotinin, $1 \mu \mathrm{g} / \mathrm{ml}$ leupeptin, and $1 \mu \mathrm{g} / \mathrm{ml}$ pepstatin for $20 \mathrm{~min}$. The cell lysates were then centrifuged at $12,000 \mathrm{x} \mathrm{g}$ for $15 \mathrm{~min}$, and protein concentrations were determined using the Bicinchoninic Acid Protein Assay kit (Beyotime, Jiangsu, China). Total cell protein (20 $\mu \mathrm{g} /$ lane) was separated by 10 or $12 \%$ SDS-PAGE followed by transfer to PVDF membranes. The membranes were blocked for $1 \mathrm{~h}$ in Tris-buffered saline containing 0.05\% Tween-20 (TBST), with 5\% nonfat dry milk. The membranes were then incubated with rabbit polyclonal antibodies against phospho-JNK1/2, phospho-ERK1/2, phospho-p38, phospho-p53, JNK1/2, ERK1/2, p38, cytochrome $c$, Bax, Bak, caspase-9, PARP or $\beta$-actin overnight at $4^{\circ} \mathrm{C}$. Following primary antibody incubation the membranes were washed with TBST and incubated
Table I. Primer seqences used for quantitative polymerase chain reaction.

\begin{tabular}{ll}
\hline Gene & \multicolumn{1}{c}{ Primer sequence (5'-3') } \\
\hline Bax & F: AAGCTGAGCGAGTGTCTCAAG \\
& R: CAAAGTAGAAAAGGGCGACAAC \\
Bak & F: AGGACACAGAGGAGGTTTCC \\
& R: ATAGCGTCGGTTGATGTCGT \\
JNK & F: CTTTGCCAAGTGATTCAGATGGA \\
& R: TTACTGGGCTTTAAGTCCGATG \\
Caspase-9 & F: CTAACAGGCAAGCAGCAAAGT \\
& R: GACATCACCAAATCCTCCAGA \\
PARP & F: AGGACGACAAGGAAAACAGGTA \\
& R: CATAGTCAATCTCCAGGGGGTA \\
GAPDH & F: AGAAGGCTGGGGCTCATTTG \\
& R: AGGGGCCATCCACAGTCTTC \\
\hline
\end{tabular}

F, forward; R, reverse.

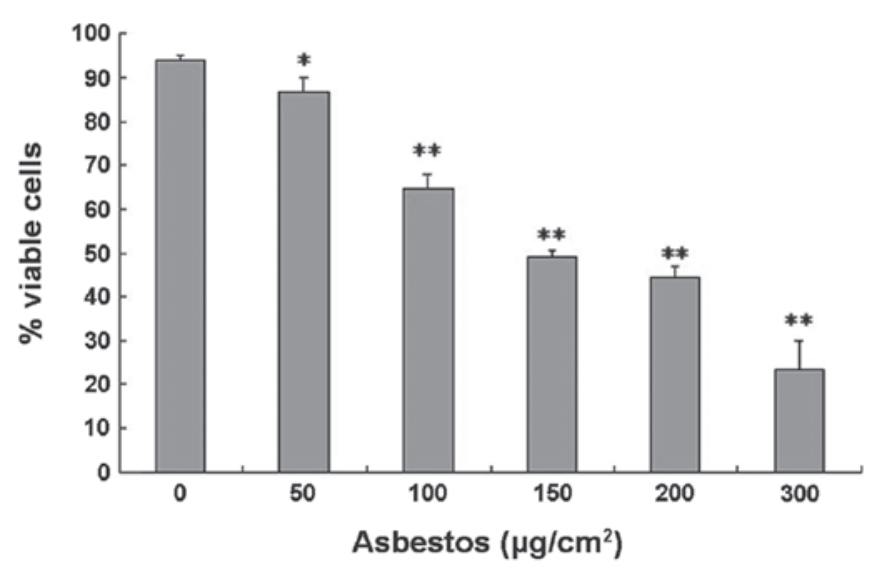

Figure 1. Effects of increasing concentrations of chrysotile asbestos on A549 human bronchoalveolar carcinoma cell viability. The viability of the cells was determined by trypan blue exclusion assay using a hemacytometer. The cell viability was shown to be significantly different between the chrysotile asbestos-treated samples and controls. The cell viability rates are expressed as percentages of the control values. The values represent the means \pm standard deviation of three independent experiments. The statistical significance of the results was analyzed by the Student's t-test, ${ }^{*} \mathrm{P}<0.05,{ }^{* *} \mathrm{P}<0.01$, vs control.

for $1 \mathrm{~h}$ with goat anti-rabbit immunoglobulin G-conjugated horseradish peroxidase-conjugated secondary antibody. The antibody-reactive bands were revealed using an enhanced chemiluminescence reagent (GE Healthcare, Little Chalfont, UK) and exposed to radiographic film.

Real-time quantitative polymerase chain reaction (PCR) $(q P C R)$ analysis. The cells were treated with chrysotile asbestos for the indicated times, followed by extraction of total RNA using TRIzol reagent (Invitrogen Life Technologies, Carlsbad, CA, USA) according to the manufacturer's instructions. Total RNA $(1 \mu \mathrm{g})$ was reverse-transcribed into cDNA using PrimeScript RT Enzyme mix at $37^{\circ} \mathrm{C}$ for $15 \mathrm{~min}$, followed by an $85^{\circ} \mathrm{C}$ incubation for $5 \mathrm{~s}$. Specific primers for real-time qPCR are detailed in Table 1. GAPDH was used as an internal control. 
A

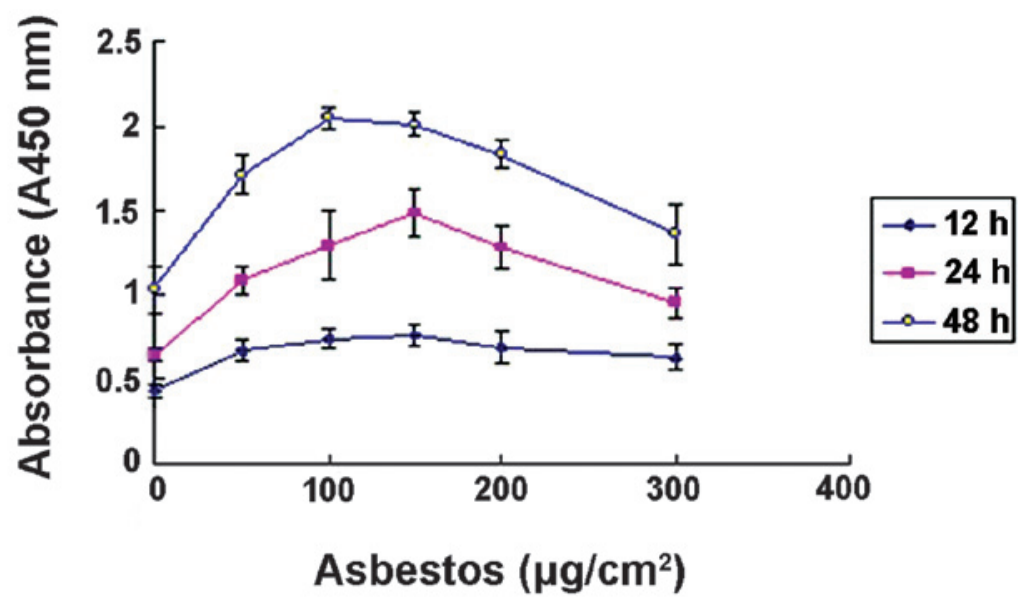

B
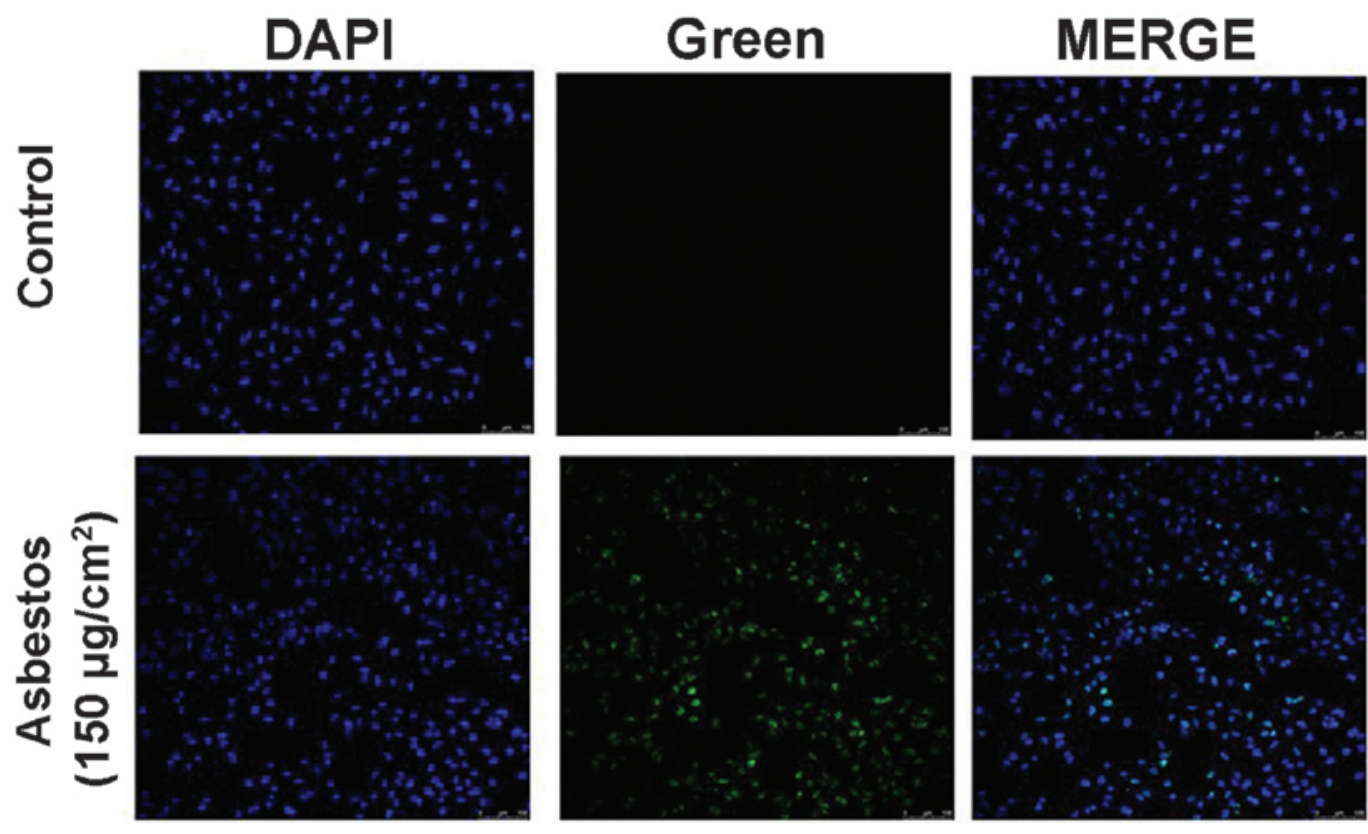

Figure 2. Induction of apoptosis by chrysotile asbestos in A549 human bronchoalveolar carcinoma cells. (A) A dose and time-dependent increase in apoptosis in A549 cells was observed following chrysotile asbestos treatment, as determined by a cellular DNA fragmentation ELISA. The data represent the means \pm standard deviation of three independent experiments. (B) A terminal deoxynucleotidyl transferase-mediated dUTP nick end labeling assay of asbestos-induced A549 cells was performed following an incubation with $150 \mu \mathrm{g} / \mathrm{cm}^{2}$ chrysotile asbestos for $24 \mathrm{~h}$. The apoptotic nuclei stained green, whereas all nuclei stained blue (DAPI). Magnification, x400. Results are representative of three independent experiments. H, hours; nm, nanometers.

Amplification was performed in a $20 \mu 1$ total reaction volume using real-time SYBR ${ }^{\circledR}$ Green PCR reagent in a LightCycler $^{\circledR}$ 480II Real-Time thermal cycler (Roche). The cycling conditions were as follows: $95^{\circ} \mathrm{C}$ for $30 \mathrm{~s}$, followed by 40 cycles of $95^{\circ} \mathrm{C}$ for $5 \mathrm{~s}$ and $60^{\circ} \mathrm{C}$ for $20 \mathrm{~s}$. Melting-curve analysis was performed for each primer set, to ensure that no primer dimers or nonspecific amplification was present under the optimized cycling conditions. The fold difference in mRNA expression was determined using the relative quantification method, with normalization to GAPDH mRNA, by comparing the relative cycle threshold $(\mathrm{Ct})$ changes between the control and the experimental samples. The fold change was calculated from the mean of the control group for each individual sample, including individual control samples, to assess variability within the groups.
Statistical analysis. The data are presented as the means \pm standard deviation. Statistical significance was evaluated using a Student's t-test. When more than one group was compared with a control, the significance was evaluated according to a one-way analysis of variance, and a Duncan's post hoc test was applied to identify group differences. A P $<0.05$ was considered to indicate a statistically significant difference. The statistical package SPSS, version 11.0 for Windows (SPSS Inc., Chicago, IL, USA) was used for statistical analyses.

\section{Results}

Chrysotile asbestos decreases cell viability and induces apoptosis in A549 cells. To examine chrysotile asbestos-induced cytotoxicity on A549 cells, the effects of chrysotile asbestos 
A
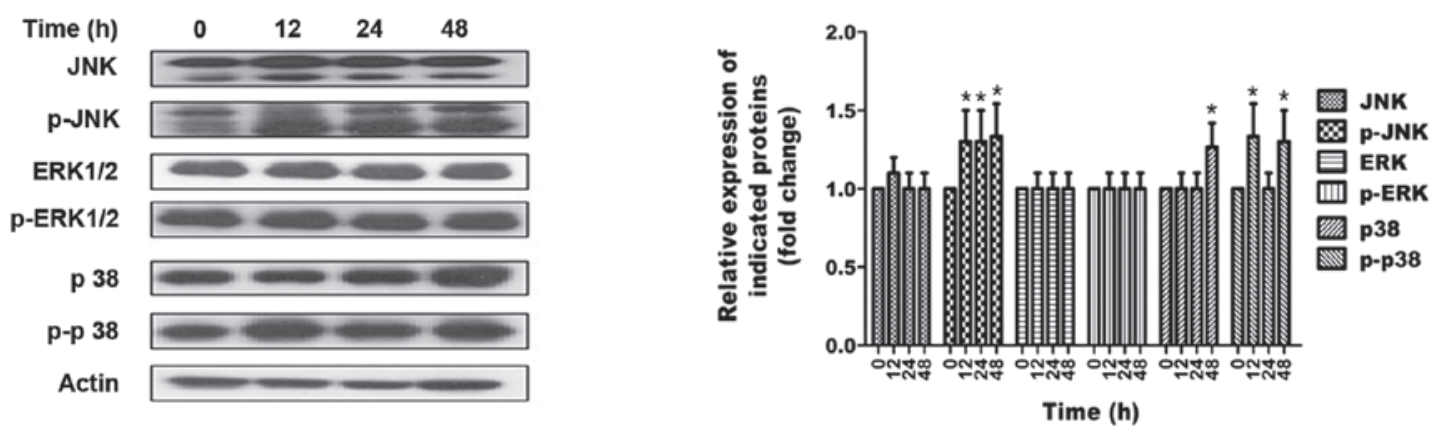

B
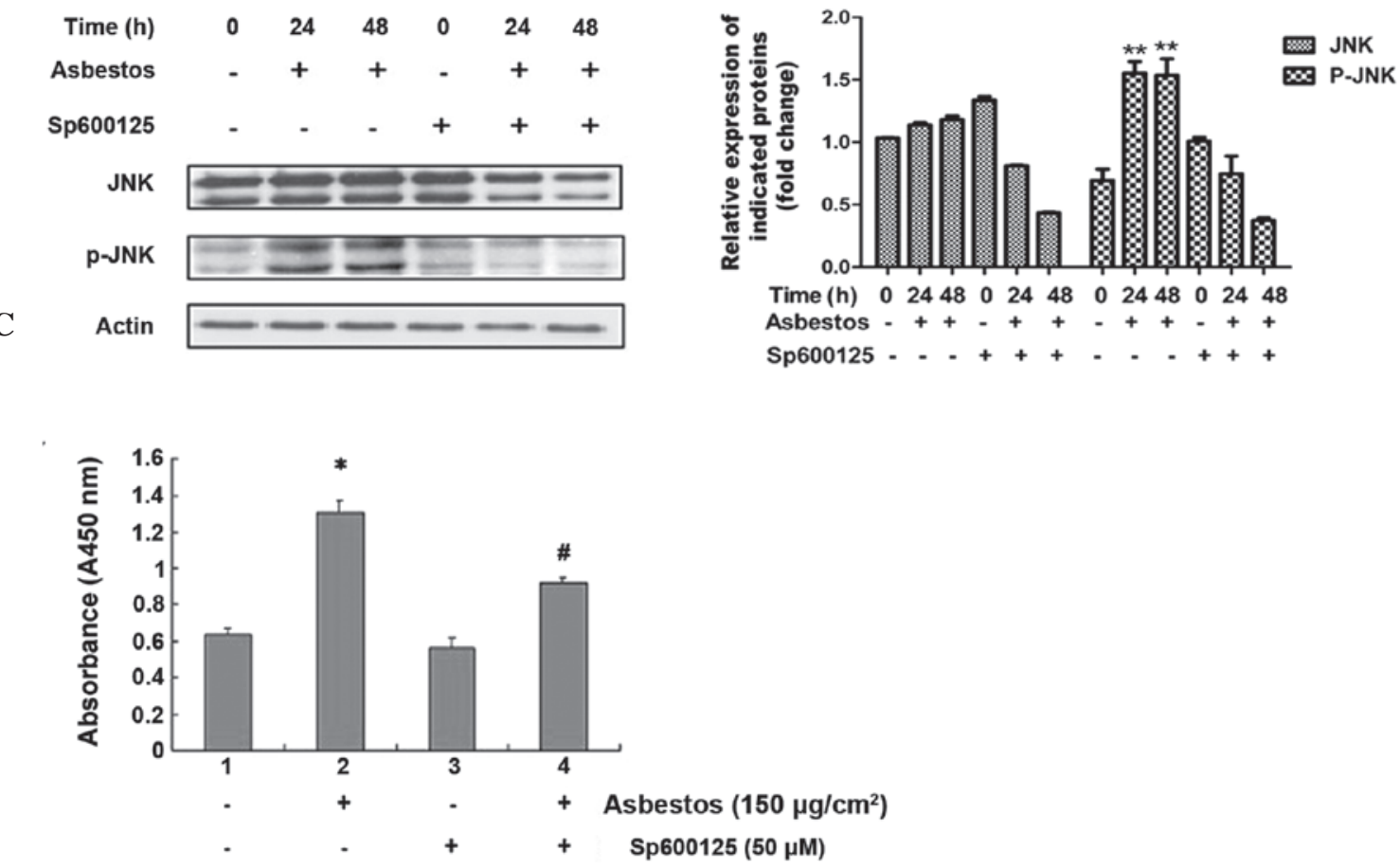

Figure 3. Effects of chrysotile asbestos on mitogen-activated protein kinase (MAPK) activation in A549 human bronchoalveolar carcinoma cells. (A) A549 cells were left untreated or were treated with chrysotile asbestos $\left(150 \mu \mathrm{g} / \mathrm{cm}^{2}\right)$ for $12,24 \mathrm{or} 48 \mathrm{~h}$, and the phosphorylation of c-Jun N-terminal kinase (JNK)-1/2, extracellular signal-regulated kinase (ERK)-1/2 and p38-MAPK were assessed by western blotting. The results are representative of three independent experiments. (B) A549 cells were treated with chrysotile asbestos $\left(150 \mu \mathrm{g} / \mathrm{cm}^{2}\right)$ for $24 \mathrm{or} 48 \mathrm{~h}$ in the absence or presence of the JNK specific inhibitor SP600125 (50 $\mu \mathrm{M}$ for $5 \mathrm{~h}$ prior to chrysotile asbestos treatment), and the phosphorylation of JNK protein was examined by western blotting. The results are representative of three independent experiments. (C) A549 cells were pretreated with $50 \mu \mathrm{M} \mathrm{SP} 600125$ for $5 \mathrm{~h} \mathrm{prior}$ to $150 \mu \mathrm{g} / \mathrm{cm}^{2}$ asbestos treatment. Following $24 \mathrm{~h}$ incubation, the apoptotic fragmentation was assessed with a cellular DNA fragmentation ELISA. The values shown represent the means \pm standard deviation from three independent experiments. The statistical significance of the results was analyzed by a Student's t-test, ${ }^{\text {"P }}<0.05$ vs. untreated control; " $\mathrm{P}<0.05$ vs. asbestos-treated cells. H, hours; JNK, c-Jun $\mathrm{N}$-terminal kinase; ERK, extracellular signal-regulated kinase; nm, nanometers.

on cell survival were determined. The cells were treated for $24 \mathrm{~h}$ with increasing concentrations of chrysotile asbestos, ranging from $50-300 \mu \mathrm{g} / \mathrm{cm}^{2}$. As the concentration of chrysotile asbestos increased there was a significant decrease in the number of viable cells, as assessed using the trypan blue exclusion assay. For the control untreated A549 cells, the viability was $93.87 \%$, and for the cells treated with chrysotile asbestos $\left(50,100,150,200,300 \mu \mathrm{g} / \mathrm{cm}^{2}\right)$, viability was $86.5,64.93,49.1$, 44.43 , and $23.63 \%$, respectively (Fig. 1). To further investigate whether chrysotile asbestos induces apoptosis in A549 cells, the levels of cellular DNA fragmentation, a hallmark of apoptotic cell death, were assessed. The results indicated that chrysotile asbestos induced DNA fragmentation in a dose- and time-dependent manner, with the levels peaking at $\sim 100-150 \mu \mathrm{g} / \mathrm{cm}^{2}$ chrysotile asbestos (Fig. 2A). To verify these findings, DNA cleavage was assayed by TUNEL staining, following $24 \mathrm{~h}$ exposure of A549 cells to chrysotile asbestos. Chrysotile asbestos led to an increased intensity of green fluorescence in the nuclear region of the cells (Fig. 2B), further confirming that chrysotile asbestos may induce apoptotic cell death.

Chrysotile asbestos induces apoptosis in A549 cells, via the JNK-MAPK signaling pathway. MAPKs have an important role in certain apoptotic signaling pathways. Therefore, the possible role of MAPKs in chrysotile asbestos-induced A549 cell apoptosis was determined. As compared with the control untreated cells, the chrysotile asbestos-treated A549 cells had significantly increased levels of phosphorylated (activated) JNK1/2 protein, but not of phosphorylated ERK1/2 or 
A

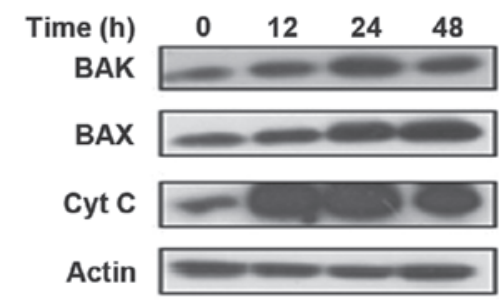

B

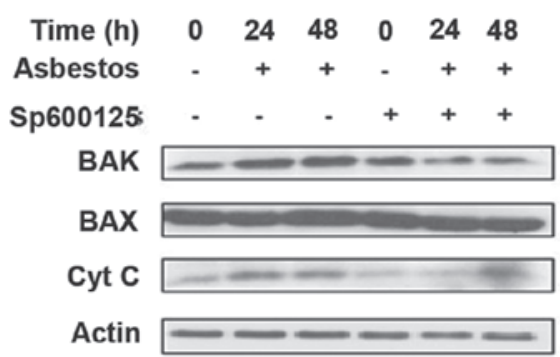

C

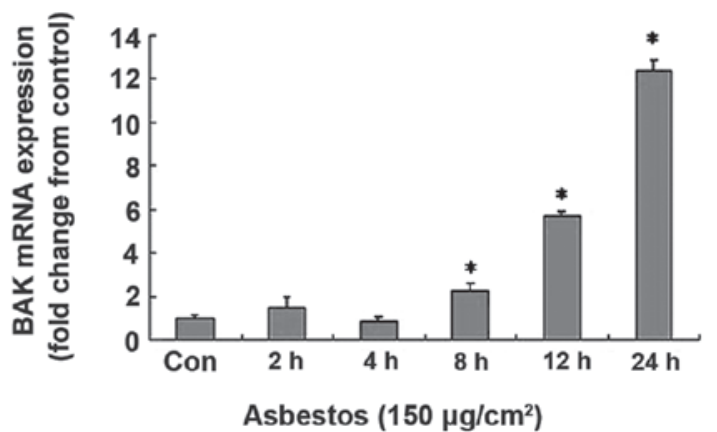

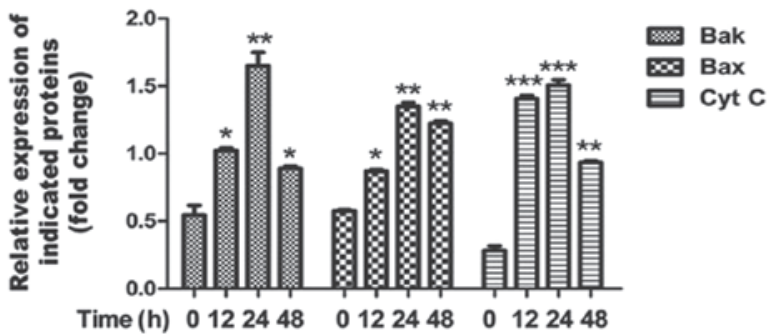
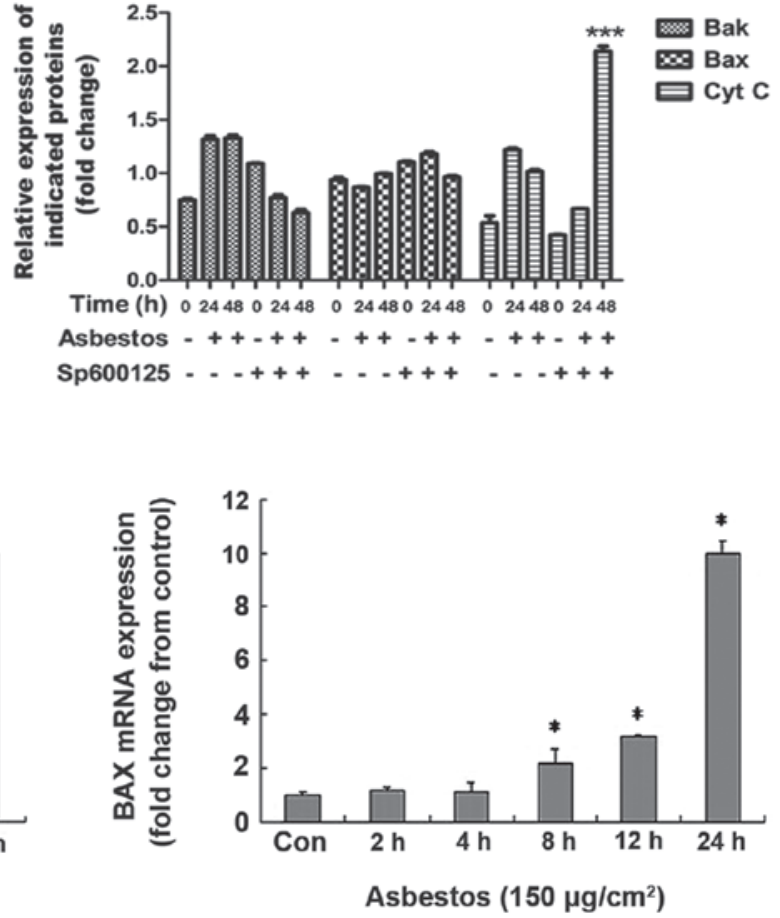

Figure 4. Analysis of mitochondrial dysfunction in chrysotile asbestos-treated A549 human bronchoalveolar carcinoma cells. (A) The cells were either left untreated or were treated with chrysotile asbestos $\left(150 \mu \mathrm{g} / \mathrm{cm}^{2}\right)$ for 12, 24 or $48 \mathrm{~h}$, and the expression of pro-apoptotic genes Bak and Bax, and cytochrome $\mathrm{c}$ was assessed by western blotting. The results are representative of three independent experiments. (B) c-Jun N-terminal kinase (JNK) inhibitor SP600125 (50 $\mu \mathrm{M}$ for $5 \mathrm{~h}$ ) was added to A549 cells prior to treatment with chrysotile asbestos $\left(150 \mu \mathrm{g} / \mathrm{cm}^{2}\right.$ for $\left.0,24 \mathrm{or} 48 \mathrm{~h}\right)$, Bax/Bak, and cytochrome c levels were examined by western blotting. The results are representative of three independent experiments. (C) The mRNA levels of Bak and Bax were assessed by quantitative polymerase chain reaction following the treatment of A 549 cells with chrysotile asbestos ( $150 \mu \mathrm{g} / \mathrm{cm}^{2}$ for $0,2,4,8,12$ or $\left.24 \mathrm{~h}\right)$. The data represent the means \pm standard deviation from three independent experiments. The statistical significance of the results was analyzed by a Student's t-test, ${ }^{\text {P }<0.05 ~ v s . ~ u n t r e a t e d ~ c o n t r o l . B a x, ~ B ~ c e l l ~ l y m p h o m a-2 ~(B c l-2) ~ a s s o c i a t e d ~ X ~ p r o t e i n ; ~ B a k, ~ B c l-2 ~ h o m o l o h o u s ~ a n t a g o n i s t ~ k i l l e r ; ~ C y t ~ C, ~ c y t o c h r o m e ~ c ; ~}$ h, hours; Con, control.

p38 (Fig. 3A). The effects of chrysotile asbestos on the JNK1/2 pathway could be reversed by pre-treatment of the cells with the JNK inhibitor SP600125 (Fig. 3B). A marked increase in the relative expression of JNK mRNA was observed following chrysotile asbestos exposure $\left(150 \mu \mathrm{g} / \mathrm{cm}^{2}\right)$ (Fig. 3C). To investigate the role of JNK in asbestos-induced A549 cell death, apoptosis levels were assessed following treatment with SP600125 (Fig. 3D). Chrysotile asbestos-induced apoptosis was partially decreased by treatment with SP600125. These results further suggest that JNK has a role in chrysotile asbestos-induced apoptosis of A549 cells.

Chrysotile asbestos induces intrinsic apoptosis in A549 cells, and inhibition of JNK is protective. The Bcl-2 family of pro- and anti-apoptotic proteins modulate the stability of the mitochondrial membrane, which determines whether or not the intrinsic apoptosis pathway is activated (18). To investigate whether the apoptotic response to chrysotile asbestos is mediated through this pathway, levels of pro-apoptotic Bax and Bak were assessed, using western blotting and qPCR. As shown in Fig. 4A, chrysotile asbestos treatment induced a time-dependent increase in the levels of Bax and Bak protein. As confirmation, the release of cytochrome $c$ from the mitochondria into the cytosol was also shown to be markedly increased in response to chrysotile asbestos treatment. The increases in Bax/Bak and cytochrome $c$ expression levels were reversed by pretreatment with SP600125, suggesting that JNK signaling regulates the effects on mitochondrial stability by chrysotile asbestos (Fig. 4B). Furthermore, $150 \mu \mathrm{g} / \mathrm{cm}^{2}$ chrysotile asbestos induced an increase in the mRNA expression of Bax/Bak (Fig. 4C and D), thus suggesting that the regulation may occur at the transcriptional level. 
A

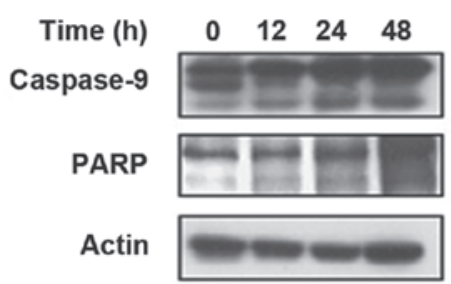

B

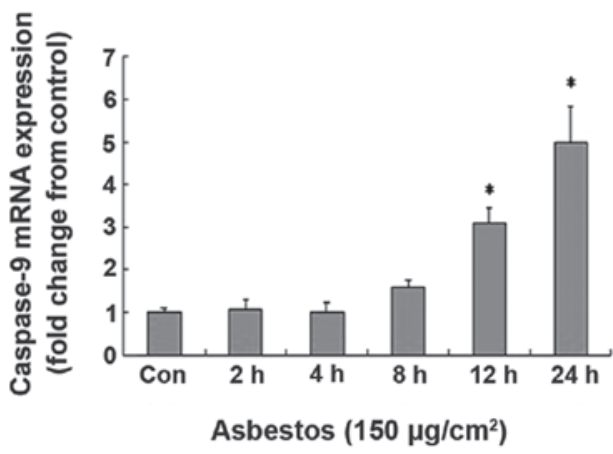

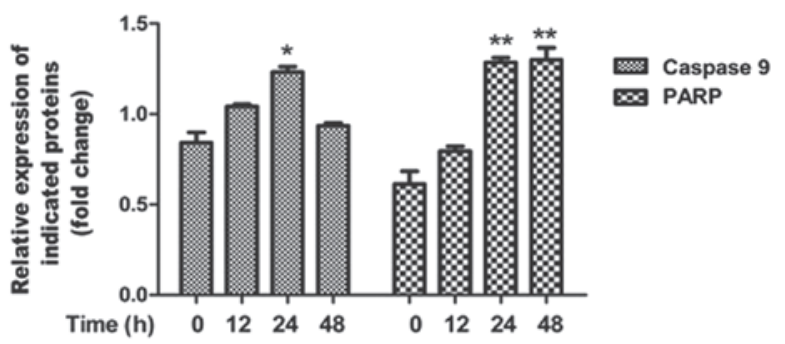

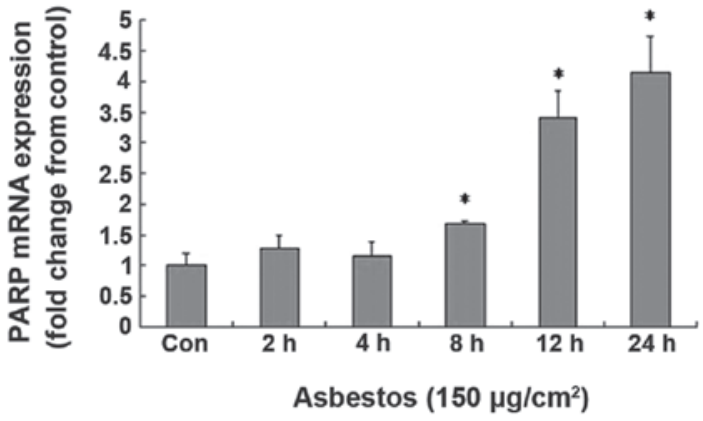

C
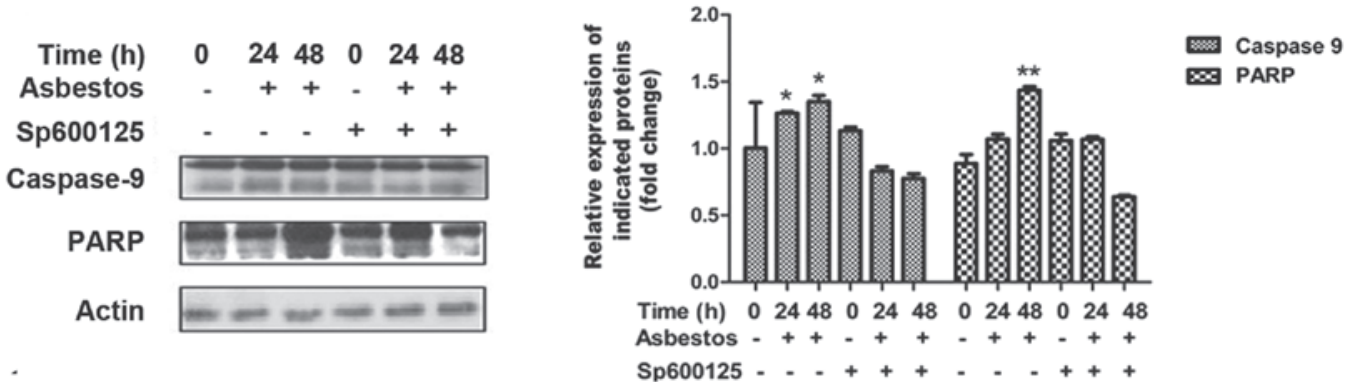

Figure 5. Chrysotile asbestos induces caspase activation and cleavage of poly (ADP-ribose) polymerase (PARP) in A549 human bronchoalveolar carcinoma cells. (A) The cells were treated with chrysotile asbestos $\left(150 \mu \mathrm{g} / \mathrm{cm}^{2}\right)$ for 12,24 or $48 \mathrm{~h}$, and the cleavage of caspase- 9 and PARP was assessed by western blotting. The results are representative of three independent experiments. (B) The cells were treated with chrysotile asbestos $\left(150 \mu \mathrm{g} / \mathrm{cm}^{2}\right)$ for $0,2,4,8,12$ or $24 \mathrm{~h}$, and caspase-9 and PARP mRNA expression was detected by quantitative polymerase chain reaction. The values shown represent the means \pm standard deviation from three independent experiments. (C) A549 cells were treated with chrysotile asbestos $\left(150 \mu \mathrm{g} / \mathrm{cm}^{2}\right)$ for 0,24 or $48 \mathrm{~h}$ in the absence or presence of c-Jun N-terminal kinase (JNK) inhibitor SP600125 (50 $\mu \mathrm{M}$ for $5 \mathrm{~h}$ ), and caspase-9 and PARP were then examined by western blotting. The results are representative of three independent experiments. The statistical significance of the results was analyzed by a Student's t-test ("p<0.05 vs. untreated control). Con, control; h, hours.

Chrysotile asbestos induces A549 cell cleaved caspase-9 and PARP, and inhibition of JNK is protective. Caspase-9 and PARP, a substrate of caspase-3, represent two additional cellular proteins that are known to be activated during apoptotic signaling (19). To determine whether these proteins are activated by chrysotile asbestos, the relative protein and mRNA expression levels were determined following treatment. As shown in Fig. 5A and B, a marked increase in protein and mRNA expression is observed for both caspase- 9 and PARP, following chrysotile asbestos treatment. Furthermore, caspase- 9 and PARP activation were blocked by the JNK inhibitor SP600125, verifying the role for JNK in mediating chrysotile asbestos-induced cell death (Fig. 5C).

\section{Discussion}

Asbestos-related pulmonary diseases remain an important long-term health concern world-wide. This is in part due to the vast amount of fibers mined and used for numerous industrial purposes and the long lag phase between exposure to the fibers and initiation of disease, which can be between 20-40 years (20). The U.S. Environmental Protection Agency has banned the production and use of all types of asbestos (20). However, in some developing countries, including China, asbestos fibers, especially chrysotile, are still widely used as a construction material. Although there are numerous pathophysiological mechanisms accounting for asbestos-induced pulmonary toxicity, AEC apoptosis is widely implicated but by mechanisms which are not yet fully understood $(1,2,4,7)$. Furthermore, the role of chrysotile asbestos in mediating human AEC apoptosis is not well characterized. The present study showed that chrysotile asbestos induced intrinsic apoptosis in human A549 lung epithelial cells, in a dose- and time-dependent manner, as assessed by cell viability, DNA fragmentation, and expression of Bax-Bak, cleaved caspase-9 and PARP activation. Furthermore, it was determined that chrysotile asbestos-induced A549 cell intrinsic apoptosis was mediated by JNK activation. Overall, these results suggest that 


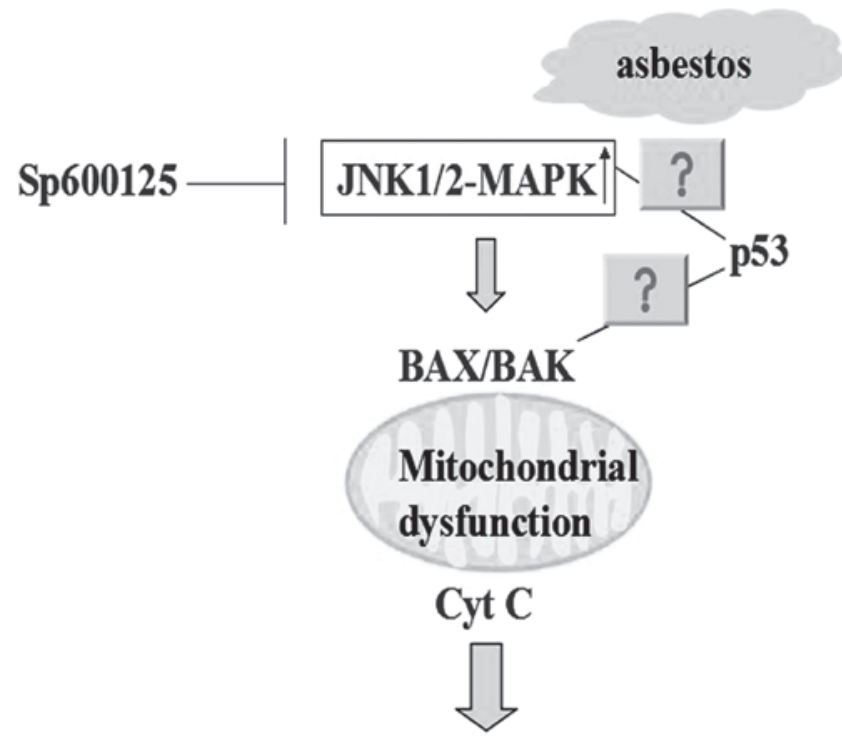

Caspase-9

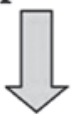

PARP degradation

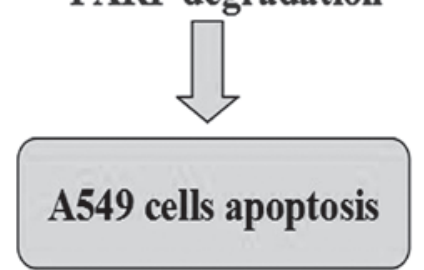

Figure 6. A schematic representation of the molecular mechanism proposed for the induction of apoptosis by chrysotile asbestos in A549 human bronchoalveolar carcinoma cells. The results from the present study support a pathway by which chrysotile asbestos induces apoptosis via the activation of c-Jun N-terminal kinase (JNK), resulting in mitochondrial disruption, the release of cytochrome $\mathrm{c}$ and finally the activation of a cascade of caspases JNK, c-Jun N-terminal kinase; MAPK, mitogen-activated protein kinases BAX, B cell lymphoma-2 (Bcl-2) associated X protein; BAK, Bcl-2 homologous antagonist killer; Cyt C, cytochrome c; PARP, poly (ADP-ribose) polymerase; Sp00125, JNK inhibitor.

chrysotile-induced AEC JNK activation is a novel signaling pathway which may be relevant in the pathophysiology of asbestos-related pulmonary diseases.

Apoptosis, also known as programmed cell death, is an important mechanism by which cells with DNA damage are eliminated without the elicitation of an inflammatory response (21). Apoptotic cells are characterized by nuclear chromatid condensation, endonuclease activation resulting in DNA fragmentation, translocation of phosphatidylserine to the outer plasma membrane, and the generation of double-stranded DNA breaks (22-24). Asbestos has been shown to trigger apoptosis in all relevant lung target cells (25). Previous studies have shown that low levels of asbestos $\left(<0.5 \mu \mathrm{g} / \mathrm{cm}^{2}\right)$ promote the entry of cells into the S-phase of the cell cycle without inducing apoptosis, whereas higher levels of asbestos $\left(1.0-5.0 \mu \mathrm{g} / \mathrm{cm}^{2}\right)$ impede entry into the S-phase and induce apoptosis (25-28). The results of the present study indicated that chrysotile asbestos induced the greatest extent of apoptosis in A549 cells at a concentration of $150 \mu \mathrm{g} / \mathrm{cm}^{2}$ for $48 \mathrm{~h}$, likely due to the lower cytotoxicity of chrysotile asbestos as compared with other types of asbestos (20). A previous study showed that asbestos induces protein kinase $\mathrm{C} \delta(\mathrm{PKC} \delta$ )-dependent protein kinase D (PKD) phosphorylation in lung epithelial cells (8). PKC $\delta$-dependent PKD phosphorylation by asbestos is causally linked to a cellular pathway that involves the phosphorylation of both ERK1/2 and JNK1/2, which have opposing roles in the apoptotic response induced by asbestos (8). Furthermore, numerous studies have previously shown that AEC apoptosis, via caspase-3 and -9 activation, mediates asbestos-induced lung injury $(11,29,30)$. The results of the present study showed that, in high doses, chrysotile asbestos triggers apoptosis of A549 cells by inducing the release of cytochrome $c$. This release was shown to be accompanied by a marked increase in the activation of Bax/Bak and caspase-9. Furthermore, the exposure of A549 cells to chrysotile asbestos resulted in a significant increase in the relative expression levels of Bax/Bak and Caspase-9 mRNA. These results indicate that chrysotile asbestos induces A549 cell apoptosis through the mitochondria-dependent pathway.

The MAPKs (p38, ERK, and JNK) are activated in response to various cellular stressors or stimuli, including oxidative stress, lipopolysaccharide and tumor necrosis factor- $\alpha$ (31-33). Generally, the JNK and p38 MAPK pathways are considered as "stress-activated protein kinases", which have an essential role in inflammation and apoptosis (34). The ERK pathway has been shown to be important in cellular differentiation and proliferation, as well as in cell survival (34). To evaluate the involvement of the MAPK signaling pathways in chrysotile asbestos-induced A549 cell apoptosis, the expression of MAPKs, following treatment with chrysotile asbestos, was determined in the present study (12, 24 and 48h). Chrysotile asbestos led to a significant time-dependent activation of the JNK protein, whereas there were no significant changes in the activation of p38 and ERK (Fig. 3). JNK has previously been shown to phosphorylate mitochondrial membrane proteins, such as the Bcl-2 family members, activating their apoptotic function $(35,36)$. Furthermore, caspases transduce the signals of most apoptosis-inducing factors (37), and PARP is one of the main cleavage targets of caspase- 3 and a main effector in cell apoptosis (19). Therefore, to determine the molecular mechanisms of chrysotile asbestos-induced apoptosis in A549 cells, the expression levels of Bax/Bak, caspase-9 and PARP were determined, following the treatment of A549 cells with chrysotile asbestos. Treatment with chrysotile asbestos increased the expression of each of these proteins at different time points. Moreover, the JNK-specific inhibitor SP600125 substantially inhibited chrysotile asbestos-induced activation. Apoptosis was also significantly decreased by SP600125 pre-treatment (Fig. 4 and 5), suggesting that the JNK signaling pathway is functionally involved in chrysotile asbestos-induced A549 cell apoptosis through these downstream effectors.

In conclusion, the results of the present study revealed that chrysotile asbestos significantly decreased the viability of human A549 cells. Furthermore, chrysotile asbestos triggered mitochondrial dysfunction and intrinsic apoptotic cascades through the activation of JNK1/2 phosphorylation, which was shown to be reversed by the specific JNK inhibitor SP600125. A hypothetical model illustrating the role of the JNK signaling pathway in chrysotile asbestos-induced apoptosis is shown in Fig 6. The precise molecular mechanisms by which chrysotile-induced JNK activation triggers AEC intrinsic apoptosis, 
as well as the in vivo relevance of the present in vitro findings, requires further study. Chrysotile asbestos-induced intrinsic AEC apoptosis through a JNK-dependent mechanism may be a novel target for the modulation of chrysotile asbestos-related lung diseases.

\section{Acknowledgements}

This work was supported by grants from the Natural Science Foundation of China (no. 81172615) and by the Natural Science Foundation of Guangdong Province (no. 2012B031800223), the Science and Technology Project of Guangdong Province (no. S2012010008299), the Science and Technology Plan Projects of Zhanjiang City (no. 20201Z01101), and the VA Merit (DWK) (no. RO1ES020357).

\section{References}

1. Mossman BT, Kamp DW and Weitzman SA: Mechanisms of carcinogenesis and clinical features of asbestos-associated cancers Cancer Invest 14: 466-480, 1996.

2. Kamp DW: Asbestos-induced lung diseases: an update. Transl Res 153:143-152, 2009.

3. Liu G, Beri R, Mueller A and Kamp DW: Molecular mechanisms of asbestos-induced lung epithelial cell apoptosis. Chem Biol Interact 188: 309-318, 2010 .

4. Liu G, Cheresh P and Kamp DW: Molecular basis of asbestos-induced lung disease. Annu Rev Pathol 8: 161-187, 2013.

5. Lin Z, Liu T, Kamp DW, Wang Y, He H, Zhou X, Li D, Yang L, Zhao B and Liu G: AKT/mTOR and c-Jun N-terminal kinase signaling pathways are required for chrysotile asbestos-induced autophagy. Free Radic Biol Med 72: 296-307, 2014.

6. Heintz NH, Janssen-Heininger YM and Mossman BT: Asbestos, lung cancers, and mesotheliomas: from molecular approaches to targeting tumor survival pathways. Am J Respir Cell Mol Biol 42: 133-139, 2010.

7. Huang SX, Jaurand MC, Kamp DW, Whysner J and Hei TK: Role of mutagenicity in asbestos fiber-induced carcinogenicity and other diseases. J Toxicol Environ Health B Crit Rev 14: 179-245, 2011.

8. Buder-Hoffmann SA, Shukla A, Barrett TF, MacPherson MB, Lounsbury KM and Mossman BT: A protein kinase Cdelta-dependent protein kinase D pathway modulates ERK1/2 and JNK1/2 phosphorylation and Bim-associated apoptosis by asbestos. Am J Pathol 174: 449-459, 2009.

9. Aljandali A, Pollack H, Yeldandi A, Li Y, Weitzman SA and Kamp DW: Asbestos causes apoptosis in alveolar epithelial cells: role of iron-induced free radicals. J Lab Clin Med 137: 330-339, 2001.

10. Kamp DW, Panduri V, Weitzman SA and Chandel N: Asbestos-induced alveolar epithelial cell apoptosis: role of mitochondrial dysfunction caused by iron-derived free radicals. Mol Cell Biochem 234-235, 153-160, 2002.

11. Panduri V, Weitzman SA, Chandel N and Kamp DW: The mitochondria-regulated death pathway mediates asbestos-induced alveolar epithelial cell apoptosis. Am J Respir Cell Mol Biol 28: 241-248, 2003.

12. Zanella CL, Posada J, Tritton TR and Mossman BT: Asbestos causes stimulation of the extracellular signal-regulated kinase 1 mitogen-activated protein kinase cascade after phosphorylation of the epidermal growth factor receptor. Cancer Res 56: 5334-5338, 1996

13. Baldys A and Aust AE: Role of iron in inactivation of epidermal growth factor receptor after asbestos treatment of human lung and pleural target cells. Am J Respir Cell Mol Biol 32: 436-442, 2005.

14. Swain WA, O'Byrne KJ and Faux SP: Activation of 338 MAP kinase by asbestos in rat mesothelial cells is mediated by oxidative stress. Am J Physiol Lung Cell Mol Physiol 286: L859-L865, 2004.

15. Upadhyay D, Panduri V and Kamp DW: Fibroblast growth factor-10 prevents asbestos-induced alveolar epithelial cell apoptosis by a mitogen-activated protein kinase-dependent mechanism. Am J Respir Cell Mol Biol 32: 232-238, 2005.
16. Tamminen JA, Myllärniemi M, Hyytiäinen M, Keski-Oja J and Koli K: Asbestos exposure induces alveolar epithelial cell plasticity through MAPK-Erk signaling. J Cell Biochem 113: 2234-2247, 2012

17. Hei TK, Piao CQ, He ZY, Vannais D and Waldren CA: Chrysotile fiber is a strong mutagen in mammalian cells. Cancer Res 52: 6305-6309, 1992 .

18. Adams JM and Cory S: The Bcl-2 protein family: arbiters of cell survival. Science 281: 1322-1326, 1998.

19. Soldani C and Scovassi AI: Poly(ADP-ribose) polymerase-1 cleavage during apoptosis: An update. Apoptosis 7:321-328, 2002.

20. Ramazzini C: Asbestos is still with us: repeat call for a universal ban. Am J Ind Med 54: 168-173, 2011.

21. Li P, Nijhawan D, Budihardjo I, Srinivasula SM, Ahmad M, Alnemri ES and Wang X: Cytochrome c and dATPdependent formation of Apaf-1/caspase-9 complex initiates an apoptotic protease cascade. Cell 91: 479-489, 1997.

22. Franco R and Panayiotidis MI: Environmental toxicity, oxidative stress, human disease and the "black box" of their synergism: how much have we revealed? Mutat Res 674: 1-2, 2009.

23. Kroemer G, Galluzzi L and Brenner C: Mitochondrial membrane permeabilization in cell death. Physiol Rev 87: 99-163, 2007

24. Upadhyay D and Kamp DW: Asbestos-induced pulmonary toxicity: role of DNA damage and apoptosis. Exp Biol Med (Maywood) 228: 650-659, 2003.

25. Shukla A, Jung M, Stern M, Fukagawa NK, Taatjes DJ, Sawyer D, Van Houten B and Mossman BT: Asbestos induces mitochondrial DNA damage and dysfunction linked to the development of apoptosis. Am J Physiol Lung Cell Mol Physiol 285: L1018-L1025, 2003.

26. Shukla A, Gulumian M, Hei TK., Kamp D, Rahman Q and Mossman BT: Multiple roles of oxidants in the pathogenesis of asbestos-induced diseases. Free Radic Biol Med 34: 1117-1129, 2003.

27. Shukla A, Stern M, Lounsbury KM, Flanders T and Mossman BT: Asbestos-induced apoptosis is protein kinase $\mathrm{C}$ delta-dependent. Am J Respir Cell Mol Biol 29: 198-205, 2003.

28. Yuan Z, Taatjes DJ, Mossman BT and Heintz NH: The duration of nuclear extracellular signal-regulated kinase 1 and 2 signaling during cell cycle reentry distinguishes proliferation from apoptosis in response to asbestos. Cancer Res 64: 6530-6536, 2004.

29. Kido T, Morimoto Y, Asonuma E, Yatera K, Ogami A, Oyabu T, Tanaka I and Kido M: Chrysotile asbestos causes AEC apoptosis via the caspase activation in vitro and in vivo. Inhal Toxicol 20: 339-347, 2008.

30. Soberanes S, Panduri V, Mutlu GM, Ghio A, Bundinger GR and Kamp DW: p53 mediates particulate matter-induced alveolar epithelial cell mitochondria-regulated apoptosis. Am J Respir Crit Care Med 174: 1229-1238,2006.

31. Frazier WJ, Xue J, Luce WA and Liu Y: MAPK signaling drives inflammation in LPS-stimulated cardiomyocytes: the route of crosstalk to G-protein-coupled receptors. PLoS One 7: e50071, 2012.

32. Sim YS, Kim SY, Kim EJ, Shin SJ and Koh WJ: Impaired expression of MAPK is associated with the downregulation of TNF- $\alpha$, IL-6, and IL-10 in Mycobacterium abscessus lung disease. Tuberc Respir Dis (Seoul) 72: 275-283, 2012.

33. Soga M, Matsuzawa A and Ichijo H: Oxidative stress-induced diseases via the ASK1 signaling pathway. Int J Cell Biol 2012: 439587, 2012.

34. Xia Z, Dickens M, Raingeaud J, Davis RJ and Greenberg ME: Opposing effects of ERK and JNK-p38 MAP kinases on apoptosis. Science 270: 1326-1331, 1995.

35. Aoki H, Kang PM, Hampe J, Yoshimura K, Noma T, Matsuzaki M and Izumo S: Direct activation of mitochondrial apoptosis machinery by c-Jun $\mathrm{N}$-terminal kinase in adult cardiac myocytes. J Biol Chem 277: 10244-10250, 2002.

36. Wang H, Yang YB, Shen HM, Gu J, Li T and Li XM: ABT-737 induces Bim expression via JNK signaling pathway and its effect on the radiation sensitivity of HeLa cells. PLoS One 7: e52483, 2012.

37. Xiao F, Liu B and Zhu QX: c-Jun N-terminal kinase is required for thermotherapy-induced apoptosis in human gastric cancer cells. World J Gastroenterol 18: 7348-7356, 2012. 